\title{
Efficacy of ultrasound-guided thoracentesis catheter drainage for pleural effusion
}

\author{
${\text { WEITIAN } \mathrm{CAO}^{1} \text {, YI WANG }}^{2}$, NINGMING ZHOU ${ }^{1}$ and $\mathrm{BING} \mathrm{XU}^{1}$ \\ ${ }^{1}$ Department of Ultrasound, Shanghai No. 5 Hospital of Fudan University; ${ }^{2}$ Department of Ultrasound, \\ Huashan Hospital of Fudan University, Shanghai 200040, P.R. China
}

Received April 22, 2016; Accepted September 19, 2016

DOI: 10.3892/ol.2016.5244

\begin{abstract}
The factors influencing the efficacy of ultrasoundguided thoracentesis catheter drainage were investigated in the present study. A retrospective analysis of clinical data from 435 patients who presented with a pleural effusion was performed. Patients were divided into a control group and an intervention group. Thirty-seven patients in the control group were given standard care using pleural puncture to draw the excess fluid. The 398 patients in the intervention group were treated using ultrasound-guided thoracentesis catheter drainage. The rate of successful drainage of a pleural effusion was significantly higher $(\mathrm{P}<0.05)$, while the rate of complication was lower, in the ultrasound-guided thoracentesis cases compared to standard care treatment. In conclusion, ultrasound-guided thoracentesis catheter drainage is an efficient, safe and minimally invasive procedure to alleviate pleural effusion. The efficacy of the procedure is related to the separation of pleural effusion, drainage tube type and tube diameter.
\end{abstract}

\section{Introduction}

Pleural effusion is a relatively common complication that can result from many medical conditions such as congestive heart failure, pneumonia, cancer, liver cirrhosis and kidney disease (1-5). In clinic, the etiology is determined by specimens obtained from a series of thoracentesis $(6,7)$, and therapy uses appropriate treatment after diagnosis and puncture drainage therapy $(8,9)$. Over the years, the use of ultrasound-guided catheterization in the diagnosis and treatment of pleural effusion has increased, tending to replace the traditional puncture method (10-12).

From January 2013 to May 2014, 435 cases with different causes of pleural effusion were collected to treat with pleural

Correspondence to: Dr Yi Wang, Department of Ultrasound, Huashan Hospital of Fudan University, 12 Middle Urumqi Road, Shanghai 200040, P.R. China

E-mail: wang_yi_99@163.com

Key words: pleural effusion, thoracentesis catheter drainage, ultrasound puncture drawing fluid and ultrasound-guided thoracentesis catheter drainage and analyzed.

\section{Patients and methods}

Patients. In total, 435 patients with pleural effusion from January 2013 to May 2014 were included in the present study. The control group (group A) included 37 cases of pleural effusion that were treated using standard care pleural puncture to draw fluid. The intervention group (group B) included 398 cases of ultrasound-guided thoracentesis catheter drainage; 230 males and 205 females, with an average age of 60 years (range, 16-93 years). In the intervention group B, there were 140 separated pleural effusion cases (Fig. 1A) and 258 non-separated pleural effusion cases (Fig. 1B).

After approval of the Ethics Committee of Huashan Hospital of Fudan University and informed consent of patients or relatives were obtained, the cases were randomly divided into the control and intervention groups.

\section{Methods}

Instruments. V730 GE ultrasonic diagnostic apparatus, thoracentesis package, disposable central venous catheter package (containing 16 G drainage tube; Shanghai Puyi Medical Instruments Co., Ltd., Shanghai, China), and SKATER drainage tube (Fig. 2) (including 6 and 8 F; Anjie Tai Medical Technology Co., Ltd.).

Pleural puncture drawing fluid. For ultrasound preoperative localization or percussion localization, the site was disinfected prior to conventional puncture site and draped locally. After lidocaine was used as the local anesthetic, thoracic puncture needle was slowly inserted into the skin from the puncture site along the rib edge. When there was a break, the syringe pump was used to pump pleural effusion (the first time $<600 \mathrm{ml}$ and $\leq 1,000 \mathrm{ml}$ each time thereafter).

Pleural puncture catheter drainage. Ultrasonic localization and conventional disinfection drape was used. After lidocaine was used as the local anesthetic, thoracic puncture needle was inserted into pleural effusion under ultrasound guidance. A guide wire was used with the puncture needle to insert the drainage tube (central venous catheter or SKATER drainage tube) (Fig. 2), and the guide wire was then removed. The drainage bag was connected and the tube fixed on the body surface. Pleural effusion was drawn out periodically. 


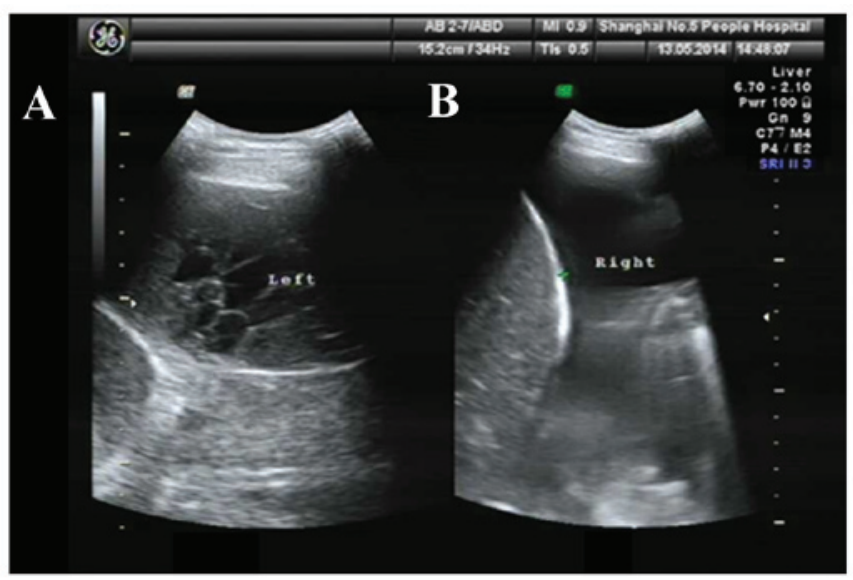

Figure 1. Ultrasound scan showing distinct pleural effusion types (A) Separate and (B) non-separated pleural effusion.

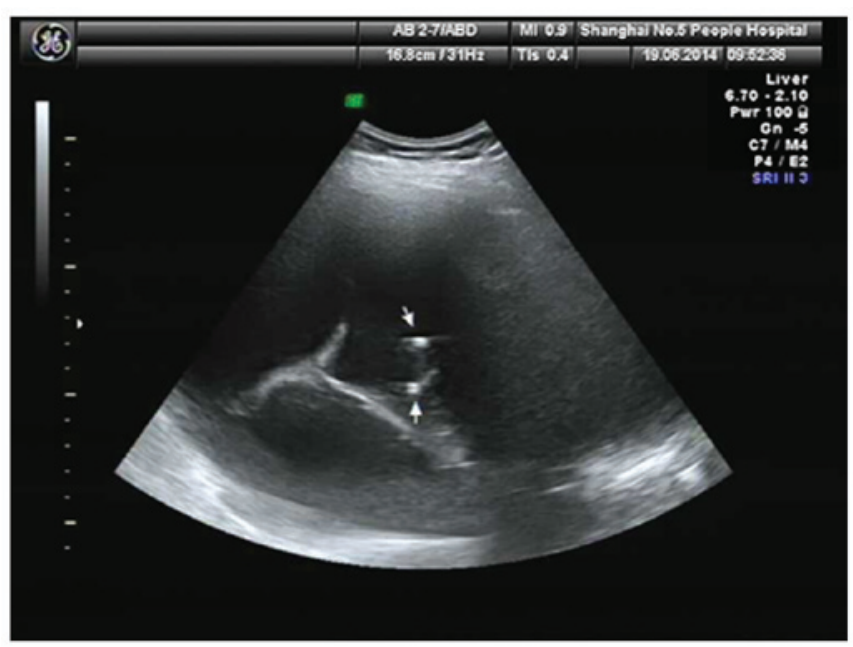

Figure 2. Ultrasound scan showing SKATER drainage tube in pleural effusion.

Pleural effusion control criteria. Complete remission (CR): Pleural effusion disappearing maintained at least 4 weeks. Partial remission (PR): Pleural effusion reduction was more than $50 \%$ and maintained 4 weeks. Stable remission (SR): Pleural effusion reduction was $<50 \%$ without a decrease or increased trend. Progressive disease (PD): No reduction or a decrease or increased trend of pleural effusion. Overall effectiveness was calculated as, $\mathrm{CR}+\mathrm{PR}$.

Statistical analysis. SPSS 19.0 statistical software (Chicago, IL, USA) was used for statistical analysis. Measurement data were analyzed using a Student's t-test. Counting data are expressed as a $\chi^{2}$ test. $\mathrm{P}<0.05$ was considered to indicate a statistically significant difference.

\section{Results}

As shown in Table I, 37 patients in group A were treated with pleural puncture and fluid was drawn a total of 57 times and the disposable puncture success rate was $84 \%$ (48/57). CR was seen in 4 cases, and PR in 15 cases (overall effectiveness: $C R+P R=19$ cases total). Furthermore, there were
Table I. Effectiveness and complication rates for standard care (group A) vs. ultrasound-guided thoracentesis (group B).

Complications

Groups N effectiveness ${ }^{\mathrm{a}}$ Pneumothorax Pleural reaction

\begin{tabular}{lrccc}
\hline A & 37 & 19 & 2 & 2 \\
B & 398 & 309 & 4 & 1 \\
P-value & & 0.001 & 0.038 & 0.020 \\
\hline
\end{tabular}

${ }^{a}$ Overall effectiveness $(\mathrm{OR})=\mathrm{CR}+\mathrm{PR}+\mathrm{SR} . \mathrm{CR}$, complete remission; PR, partial remission; SR, stable remission.

11 stable patients, and progression was observed in 7 patients. Complications were observed in 4 cases ( 2 cases of pneumothorax and 2 cases of pleural reaction).

In group B, 398 patients were treated with ultrasound-guided thoracentesis catheter drainage (419 total procedures) with a $100 \%$ success rate. CR was observed in 135 cases, PR in 174 cases, stable in 56 cases and progression in 33 cases (Table I). There were 5 complications reported ( 4 cases of pneumothorax and 1 case of pleural reaction); the drainage tube fell off in 8 cases and was obstructed in 11 cases.

In 258 cases of non-separated pleural effusion, central venous catheter was identified in 103 cases, 117 used 6F-SKATER drainage tube and 38 the 8F-SKATER (Table II). In 140 cases of separated pleural effusion, 18 were with central venous catheter, 50 using 6F-SKATER drainage tube, and 77 with 8F-SKATER.

\section{Discussion}

Numerous factors cause excess body fluid to collect in the pleural cavity to produce pleural effusion (13-17): An increase in the venous pressure of pleural capillaries, an increase of pleural permeability, and a decrease of colloid osmotic pressure of the pleural capillaries, lymphatic drainage barrier and damage.

Pleural effusion can be divided into transudate and exudate (18-21). The former mainly treats primary disease without repeated drainage, but draining of the pleural cavity is needed when the etiology is unknown, and drainage treatment should be done regardless of tuberculosis, tumor or purulence of exudate.

When excessive pleural effusion leads to dyspnea, both transudate and exudate need to be drained to improve breathing (22). Traditional puncture drainage operation requires is repeated, bringing suffering to patients many times, and increases the reaction of hemothorax, pneumothorax and pleura and the risk of infection (23). Traditional puncture drainage operation require repeated conduction and increases the chance of hemothorax, pneumothorax and risk of infection.

A pleural puncture tube can be drained repeatedly in one operation, reducing the risk of complications. In particular, the application of central venous catheters in pleural effusion has proven to be an effective, safe and economical method $(24,25)$. The first and crucial step of thoracentesis is choosing a puncture point. 
Table II. Influence of drainage tube on pleural effusion treatment success.

\begin{tabular}{|c|c|c|c|c|c|c|c|}
\hline \multirow[b]{2}{*}{ Case } & \multicolumn{2}{|c|}{$\begin{array}{c}16 \mathrm{G} \text { central } \\
\text { venous catheter }\end{array}$} & \multicolumn{2}{|c|}{$\begin{array}{l}6 \text { F-SKATER } \\
\text { drainage tube }\end{array}$} & \multicolumn{2}{|c|}{$\begin{array}{l}8 \text { F-SKATER } \\
\text { drainage tube }\end{array}$} & \multirow[b]{2}{*}{$\mathrm{P}$-value } \\
\hline & $\mathrm{N}$ & $\mathrm{OR}^{\mathrm{b}}$ & $\mathrm{N}$ & OR & $\mathrm{N}$ & OR & \\
\hline Non-separation & 103 & 89 & 117 & 100 & 38 & 34 & 0.822 \\
\hline Separation & 13 & 5 & 50 & 26 & 77 & 55 & $0.018\left(0.037^{\mathrm{a}}\right)$ \\
\hline P-value & \multicolumn{2}{|c|}{0.000} & \multicolumn{2}{|c|}{0.000} & \multicolumn{2}{|c|}{0.034} & \\
\hline
\end{tabular}

${ }^{\mathrm{a} C o m p a r i s o n}$ of the therapeutic effect of $6 \mathrm{~F}$ and $8 \mathrm{~F}$ SKATER drainage tube in the separation of pleural effusion. ${ }^{\mathrm{b}}$ Overall effectiveness $(\mathrm{OR})=\mathrm{CR}+\mathrm{PR}+\mathrm{SR}$. CR, complete remission; PR, partial remission; SR, stable remission.

There are three clinical methods for choosing a puncture point to treat pleural effusion: Blind puncture, ultrasonic locating of puncture and ultrasound-guided puncture $(26,27)$. Blind puncture is used by clinicians to locate the puncture according to imaging data, experience and percussion; ultrasound puncture locates the puncture point via ultrasound, then clinicians continue to puncture the locating point back on the ward, and ultrasound-guided puncture is performed under real-time monitoring.

Ultrasound location often has associated problems, such as failure to puncture the exact ultrasound localization, or the pleural effusion drainage is not satisfactory (28). To ensure the safety of the puncture, clinicians mainly choose the effusion surface of largest area as a puncture point. However, after drainage, with the reduction of pleural effusion, lung recruitment or diaphragm elevation, the drainage tube area has no effusion, and the closeness to the pleura causes poor drainage and drainage is incomplete. The ultrasound-guided catheterization cannot only avoid the above factors, but can also guide and correct the placement of the drainage tube. Compared to the traditional thoracentesis, it has a lower incidence of pneumothorax and pleural reaction.

Pleural effusion caused by congestive heart failure and hypoalbuminemia is mostly transudate, which is low in protein content, with a few cells and good fluidity $(29,30)$. While the exudate of tuberculous pleurisy and the malignant pleural effusion produced by malignancy invasion in pleura are high in protein content, with many cells, tending to form fibrous bands, separation and even honeycomb. The existence of separation reduces the fluidity of pleural effusion. Fibrous bands block the drainage, and interfere or limit the diffusion of drug injected in the thoracic cavity. Early drainage of separated pleural effusion is important, especially for tuberculous pleural effusion, to reduce adhesions between pleural and lung tissue or decrease pleural thickening $(31,32)$. To achieve early recovery of lung function, the key is a clean drainage of pleural effusion on the basis of reasonable and standard anti-tuberculosis therapy.

Currently, thoracentesis catheter drainage is mainly via central venous catheter $(24,25)$. It has the traits of flexibility and good tissue compatibility but is easily blocked. Some researchers believe that small-diameter drainage tubes (diameter, $\leq 14 \mathrm{~F}$ ) have no effect on drainage (33), but the present study shows this is not always true. For a non-separated pleural effusion drainage tube, diameter has no effect on the drainage efficacy, while for a separated pleural effusion drainage tube, diameter does affect drainage efficacy. Two kinds of drainage tubes were used: a central venous catheter and the SKATER drainage tube (34). The side aperture of central venous catheter is less than its diameter, and the drainage effect depends on the size of side holes. Central venous catheters of different diameter have small side holes, which are easily blocked by fibrous bands within separated pleural effusion, thus lowering efficacy. The SKATER drainage tube has an elongated side hole, whose diameter is greater than the drainage pipe, so its efficacy depends on the diameter of the drainage tube. Therefore, for a small-diameter drainage tube, in fibrous bands or separation within pleural effusion, the efficacy is related to the diameter. For a separated or potentially separated effusion like tuberculous pleural effusion, a drainage tube with a big side hole like SKATER should be used while a lower cost central venous catheter can be used for non-separated pleural effusions.

In conclusion, ultrasound-guided thoracentesis catheter drainage is an efficient, safe, minimally invasive procedure with a high rate of success. Its efficacy is related to the separation of pleural effusion, drainage tube type and tube diameter. The choice of the drainage tube should be based on the nature of pleural effusion, separation of pleural effusion and cost.

\section{References}

1. Bauwens AM, de Graaff CS and Boersma WG: Pleural effusion and empyema as complications of pneumonia. Ned Tijdschr Geneeskd 146: 464-469, 2002 (In Dutch).

2. Han ZJ, Wu XD, Cheng JJ, Zhao SD, Gao MZ, Huang HY, Gu B, Ma P, Chen Y, Wang JH, et al: Diagnostic accuracy of natriuretic peptides for heart failure in patients with pleural effusion: a systematic review and updated meta-analysis. PLoS One 10: e0134376, 2015.

3. Madrid A, Ortega G, Molina Boix M, Salinas F, Santesteban J, González-Conde A and Carmena R: Pleural effusion in cancer patients. Review of 118 cases. Med Clin (Barc) 80: 823-825, 1983 (In Spanish).

4. Zarogoulidis P, Chatzaki E, Hohenforst-Schmidt W, Goldberg EP, Galaktidou G, Kontakiotis T, Karamanos N and Zarogoulidis K: Management of malignant pleural effusion by suicide gene therapy in advanced stage lung cancer: a case series and literature review. Cancer Gene Ther 19: 593-600, 2012.

5. Assouad J, Barthes FP, Shaker W, Souilamas R and Riquet M: Recurrent pleural effusion complicating liver cirrhosis. Ann Thorac Surg 75: 986-989, 2003.

6. Pignotti MS, Messeri A and Donzelli G: Thoracentesis in pericardial and pleural effusion caused by central venous catheterization: a less invasive neonatal approach. Paediatr Anaesth 14: 349-351, 2004. 
7. Bhuniya S, Arunabha DC, Choudhury S, Saha I, Roy TS and Saha M: Role of therapeutic thoracentesis in tuberculous pleural effusion. Ann Thorac Med 7: 215-219, 2012.

8. Lazarev SM, Reshetov AV, Kakysheva OE, Nikolaev GV, Kirillov IuV and Volgin GN: The assessment of surgical treatment of patients with malignant pleural effusion. Vestn Khir Im I I Grek 172: 32-38, 2013 (In Russian).

9. Miraglia R, Maruzzelli L, Piazza M, Gallo G, D'Amico M, Spada M, Vitulo P and Luca A: Real-time ultrasound-guided placement of a pigtail catheter in supine position for draining pleural effusion in pediatric patients who have undergone liver transplantation. J Clin Ultrasound 44: 284-289, 2015.

10. Marchetti G, Valsecchi A, Indellicati D, Arondi S, Trigiani M and Pinelli V: Ultrasound-guided medical thoracoscopy in the absence of pleural effusion. Chest 147: 1008-1012, 2015.

11. Abusedera M and Alkady O: Ultrasound-guided pleural effusion drainage with a small catheter using the single-step trocar or modified seldinger technique. J Bronchology Interv Pulmonol 23 $138-145,2016$

12. Liu LN, Xu HX, Lu MD and Xie XY: Percutaneous ultrasoundguided thermal ablation for liver tumor with artificial pleural effusion or ascites. Chin J Cancer 29: 830-835, 2010.

13. Kolczyński A: Etiology of pleural effusion based on material from the Hospital of Lung Diseases and Tuberculosis. Pneumonol Alergol Pol 69: 239-246, 2001 (In Polish).

14. Ferreiro L, San José E, González-Barcala FJ, AlvarezDobaño JM, Golpe A, Gude F, Anchorena C, Pereyra MF, Zamarrón C and Valdés L: Eosinophilic pleural effusion: incidence, etiology and prognostic significance. Arch Bronconeumol 47: 504-509, 2011.

15. Qari FA: Etiology of pleural effusion in Western Saudi Arabia. Saudi Med J 23: 351-352, 2002.

16. Sahoo RC and Acharya PR: Pleural effusion of a dual etiology. J Assoc Physicians India 56: 55-56, 2008.

17. Neragi-Miandoab S: Surgical and other invasive approaches to recurrent pleural effusion with malignant etiology. Support Care Cancer 16: 1323-1331, 2008.

18. Vázquez F, Michelángelo $\mathrm{H}$, Trevisani $\mathrm{H}$, González $\mathrm{F}$ and de Quiros B: Differential diagnosis between exudate and transudate in pleural effusion. Medicina (B Aires) 56: 223-230 1996 (In Spanish)

19. Gümüş A, Çınarka H, Karataş M,Kırbaş A, Kayhan S and Şahin Ü: Elevated pleural copeptin levels can distinguish to exudate from transudates. Tuberk Toraks 62: 267-272, 2014 (In Turkish).

20. Garcia Pachon E and Padilla Navas I: Pleural effusion: criteria for distinguishing between transudates and exudates. An Med Interna 13: 91-94, 1996.
21. Uchiyama T: Pleural effusion (transudates and exudates). Ryoikibetsu Shokogun Shirizu pp774-777, 1994 (In Japanese).

22. Oi K, Haraguchi N, Machida S, Beppu T, Ogawa A, Yeh YF and Sasaki T: Dyspnea resulting from accumulation of pleural effusion after radical neck dissection. A case report. Oral Surg Oral Med Oral Pathol 67: 258-261, 1989.

23. Krumhaar D: Dangers and errors in pleural puncture and placing suction drainage. Langenbecks Arch Chir Suppl II Verh Dtsch Ges Chir: 191-194, 1989 (In German).

24. Madhavi P, Jameson R and Robinson MJ: Unilateral pleural effusion complicating central venous catheterisation. Arch Dis Child Fetal Neonatal Ed 82: F248-F249, 2000.

25. Wu S and Zhang M: Central venous catheter for coal workers pneumoconiosis complicated with pleural effusion and pneumothorax efficacy analysis. Zhonghua Lao Dong Wei Sheng Zhi Ye Bing Za Zhi 33: 51-53, 2015 (In Chinese).

26. Loeza-Irigoyen JA, Muñoz-Guzmán Y, Pérez-Guzmán C and Gutiérrez-Mendoza I: Thoracocentesis in patients with pleural effusion and chronic alcoholic liver disease. Rev Med Inst Mex Seguro Soc 46: 453-458, 2008 (In Spanish).

27. Kuo YL and Chan TF: Treatment of unilateral fetal pleural effusion by intrauterine thoracocentesis. Taiwan J Obstet Gynecol 51: 303-304, 2012.

28. Cavanna L, Mordenti P, Bertè R, Palladino MA, Biasini C, Anselmi E, Seghini P, Vecchia S, Civardi G and Di Nunzio C: Ultrasound guidance reduces pneumothorax rate and improves safety of thoracentesis in malignant pleural effusion: report on 445 consecutive patients with advanced cancer. World J Surg Oncol 12: 139, 2014.

29. Woodring JH: Distribution of pleural effusion in congestive heart failure: what is atypical? South Med J 98: 518-523, 2005.

30. Pais D, Kuzmenko E, Amir J and Harel L: Association of hypoalbuminemia with the presence and size of pleural effusion in children with pneumonia. Pediatrics 121: e533-e538, 2008.

31. Ferreiro L, San José ME and Valdés L: Management of parapneumonic pleural effusion in adults. Arch Bronconeumol 51: 637-646, 2015.

32. Didilescu C, Ibraim E and Iordan CM: Management of parapneumonic pleural effusion. Pneumologia 50: 196-198, 2001 (In Romanian).

33. Antunes G, Neville E, Duffy J, Ali N; Pleural Diseases Group, Standards of Care Committee, British Thoracic Society: BTS guidelines for the management of malignant pleural effusions. Thorax 58 (Suppl 2): ii29-ii38, 2003

34. Medford AR and Maskell N: Pleural effusion. Postgrad Med J 81: 702-710, 2005. 